tions of the sympathetic were absolutely annihilated.

Such is the general plan of my treatment of this pestilential fever. A more particular detail of the modifications of treatment adopted in all the complex varieties and in tricate phenomena of the disease, would require a much greater space than it would be proper at present to occupy. Such mo. difications of administration must depend upon the mode of the development of the disease, and the view which individual practitioners may take of such symptomatic exemplifications.

Wm. John Thomas, M.R.C.S.

7, Richmond Row, Liverpool. September 17 th, 1832 .

IN THE PRIVATE PRACTICE OF MR. WINDSOR.

IN the cases of cholera which have come under my care, I have found in bilious diarrhoa the cretaceous mixture, varying it occasionally with an astringent aromatic mixture, consisting of aromatic confection, catechu, and opium, to have been without exception efficient in putting a stop to that form of the disease.

In the rice-water evacuations, I have almost entirely depended upon calomel and opium, given in doses of three or three or four grains of the former and half a grain of the latter, every half hour, and when the least ptyalism was produced, the patient has been safe.

In the stage of collapse I have given ammonia, camphor, soda, opium, hot brandy. and-water, but in most cases without effect. In district and private practice, about 120 cases have come under my care in the different forms of the disease, six have died during the rice-water evacuations, ten in a state of collapse, and 104 recovered.

JAMES WINDSOR, Surg.

Liverpool, September 17 th, 1832.

\section{IN THE FRIVATF PRACTICE OF MR. KELLY.}

To the 1st and 2nd queries :-Injections composed of one drachm and a half of laudanum, with eight grains of sugar of lead, and one ounce of tincture of catechu, thrown up in eight ounces of solution of starch every two or three hours, according to the urgency of the symptoms, or until a degree of stupor is produced.

In the collapsed stage I have generally trusted to mild stimulating diet, such as beef-tea, with a small proportion of brandy, given as well by clyster as by the stomach; to the former 1 generally added an ounce of tincture of catechu for the purpose of a stimulant, as well as an astringent to retain the injection the longer, but I nover neg: lected the precaution of ordering one of the attendants to keep the injection up, by placing the hand with a fine cloch against the rectum for at least two hours each time. Of calomel, I am sorry to say, that I cannot speak so favourably as other practitioners, having never known it to succeed in the practice of others, though I am cognizant of many cases in which it was tried, it invariably failed in my own. With the saline injection I succeeded in three cases out of twelve; it therefore, I conceive, merits future trial.

\section{Hunter Street, Liverpool,}

F. Kelly, Surg. Sept. 20th, 1832.

\section{SUCCESSTUL ADMINISTRATION OF}

\section{COLD WATER}

IN THE COLLAPSE STAGE OP

\section{MALIGNANT CHOLERA.*}

Gentremen,-Dr. Shute, of Gloucester, having transmitted to your board several memorials relative to $h 1 s$ treatment of cholera with cold water, and having invited his medical brethren to make trial of the practice, it is with pleasure that I send you a case which has terminated favourably under this mode. I should not have troubled you with an isolated case, but (with this single exception) Lynn has been some weeks quite free from any trace of this devastating disease, and I consider it due to Dr. Shute, as well as the public, that the result of a particular line of treatment, whether favourable or unfavourable, should be made known without delay.

Joseph Woodfield, an itinerant ribbonweaver from Coventry, aged 27 , of a spare habit of body, came to Lynn on Sunday night, the 9 th of September, and was attacked with cholera in a most severe form at his lodgings on the following morning at five o'clock. The rice-water vomiting was extreme, as was the purging, so that when seen by Mr. Hillyard, the dispensary surgeon, at seven, only two bours after the first appearance of disease, he was in collapse, and pulseless. He was immediately conveyed to the infirmary, where the nurse of his own accord gave him a dose of cretaceous medicine, containing a few drops of laudanum, which he soon rejected. At my visit about one hour afterwards, I found him in the same state of collapse. His eyes were sunk; eyelids half-closed, showing a tunica conjunctiva with its blood- 
vessels much congested; voice whispering; fingers livid, damp, cold, and corrugated; tongue cold. We determined on putting Dr. Shute's plan into effect. The room windows were purposely left open, he was simply covered with a blanket and rug, and neither friction, counter-irritation, nor any kind of external heat was applied. He was given a pint of cold water, and whether vomiting should sueceed or not, a repetition of it was ordered as often as he should de. sire; in fact this fluid was at all times within his reach. By the middle of the day he had drunk several pints, rejecting only a part of it, and his pulse had become very slightly perceptible. In the evening the pulse was again more indistinct, scurcely to be felt, but yet he had an improved countenance and stronger voice. He had then drunk ten pints of water without further vomiting. Ordered to pursue thesame plan through the night.

Tuesday, 11th. Half-past 9, a.m. During the past 24 hours has drank 18 pints of water; pulse small but more distinct; has slept quetly at intervals, expressed himself as feeling better, and in want of food. Hands drier, warmer, and to all appearance fuller. Neither purging nor vomiting.

Wednesday, 12th. 10 o'clock. Since our last visit has druık 11 pints of water, and passed a tolerable night; warmth of body improved; singultus supervened during the night, and is rather troublesome; pulse stronger, yet soft; eonjunctiva still injected. Allowed him a teacup of arrowroot. At our afternoon visit, we found that this had been rejected, and reaction was somewhat increased, accompanied with a dry shining tongue. Bled him to five ounces, ordered a continuance of the water, and an effervescent if he chose. In the evening found his pulse improved; tongue moist; singultus still present; thirst less; no sickness; no pain in any part. Has voided urine, also a dark watery motion. During the last 24 hours has taken only seven pints of water. The blood contained a large proportion of dark crassamentum. Although no tenderness of the epigastric region was complained of, yet, with the aim of removing singultus, a blister was applied; he was however somewhat restless, and remored it before any effect could be produced.

Thursday, 13th. Continues restless, cheeks flushed; conjunctiva still suffused; intellect more dull; pulse stronger. Has drunk only five pints of water since yester. day ; passed two motions, more frculent and yellow. Bled him to six ounces, and as this did not evince the least inflammatory cluaracter, he was allowed a little broth and tea.

Friday, 14th. Still restless and sleepless through the night, although improving as respects the evacuations, both of urine and. stools, having had two motions of a good colour and firmer consistence. Exclusive of broth and tea, has drunk only five pints of water since yesterday.

Saturday, 15th. Continues the same; two feculent motions; seven pints of water consumed.

Sunday, 16th. As yesterday ; fire pints of water consumed. Was allowed a light. pudding.

Monday, 17 th. No worse in appearance, but complains that he cannot sleep. Has drunk seven pints of water in the twenty. four hours, Sumat haustum vespere, cum nl $\mathrm{xxx}$ tinctura opii.

Tuesday, 18th. Has had a tolerable night and expresses himself as feeling better; pulse good; tongue clean and moist; appetite increasing. Continue pudding, broth,; and tea; repeat the opiate. He refused however to swallow this draught, and during the night showed much impatience, with strong indications of mental aberration, which contiuued through the ensuing day. Ilas drunk eight pints of water.

Wednesday, 19th. Pulse very good; tongue quite natural; tunica conjunctiva still injected; evinces much incoherence of speech and manner. Passes a large quantity of pale limpid urine, but his bowels not having been moved since the $16 \mathrm{lh}$, be was ordered a mild aperient.

Thursday, 20th. During the whole of last night was so ungovernable as to require the strait-waistcoat and coercive confinement to bed; but this morning appeared more rational, and remained so throughout the day. His bowels not having yet been acted upon, was ordered anotber aperient. He took also a few grains of submurias $h y-$ erargiri, with a little opium in divided doses.

Friday, 21. Passed a better night, and this morning is quite himself, complaining only of the restraint which he is under. Bodily health good, excepting that his bowels have resisted the purgatives; and as he informed us that salts always aeted kindly with him, was allowed to take halt an ounce. All restraint was removed; he was permitted to be dressed, to sit up, and have builed mutton for dinner. No further derangement followed; his convalescence has been very rapid, so as to enable him to leave Lynn on foot, on Thursday the 27 th of September, with his wife and child.

1 was on the point of addressing Dr. Shute privately, in order to learn if any of his cases had manifested symptoms of mental derangement, when his third memorial appeared, which states, that two patients were affected with strong symptoms of maniacal disease. In the case of Woodfield its 
appearance was quite sudden and unex-/expectations, and led me to depend more pected, after only two or three nights of on opiates in small doses, anodyne enemata, vigilation. But a fact equally remarkable a regulated application of heat by means of was, the extremely short duration of this the hot air bath, effervescents, and more state of mind, and equally sudden cessation free use of diluents, together with bleeding, of it; although, from the tranquil circula- upon reaction, and, occasionally, at this tion, coupled with a healthy condition of period, small doses of calomel : but no patongue, secretions, and excreitions, there was tients have recovered from the collapsed not much fear of any protracted continuance.

The pathological view which 1 have always entertained of cholera, is, in a good degree, borne out by the action of cold water upon the disease. 1 have ever considered the chief, if not primary action of the poison producing this malady, to be exerted on the secerning or exhalent vessels of the alimentary canal, so affecting them as to produce an excessive and rapid exudation, or, it mav be, secretion of the serous part of the blood, and thereby to render that vital fluid, both frem quantity and quality (particularly the latter), quite unfit for circulation, giving rise to all the symptoms of collapse, and causing the absence of bile as well as urine. Inder these circumstances the desired remedy would seem to be, that which shall at one and the same time restrain the serous effusion, and renew the blood's fluidity, without depressing vitality, or being productive of excessive reaction. Now, à priori, cold water does appear to be the most appropriate mean for effecting these indications, and experience shows that it can and does affect them: for we find it, in the most perfect collapse, acting as an astringent on the secernent ressels of the bowels; we find it become absorbed, and mildly, vet efficaciously, diluting the inspissated blood; also promoting a renewed healtly action of the heart and ar. terirs, and thus, in effect, removing the depressed vitality, and restoring the natuial and customary secretions, without engendering any excessive or dangerous reaction and consecutive fever.

Independently of these considerations, cold water is that fluid for wbich the patient most craves, which is retained best on the stomach, and which may be taken ad libitum without injury. Woodfield drank, on an average, more than a gallon every twentyfour hours for eight successive days.

Before cholera appeared in Fugland, I entertained a strong objection to any pow. erful stimuli as a mean of producing reaction, under a vitality so peculiarly and strikingly depressed; therefore I was determined not to administer them at all, concentrated or largely, should the disense reach Lynn. It has visited us; and in the treatment of those brought under my care, brandy and alcohol, in any form, were almost totally excluded. Even the sparing exhibition of ammonia, ether, or the essential oils, has too frequently disappointed my

No. 476. pulseless state in a manner more satisfactory than Woodfield under the cold witer, and certainly not with less, if so little, trouble.

As I lately communicated to two widely. extended journals the practice adopted by the medical practitioners of - Lynn to mee premonitory diarrhcea, and with the bes success; as 1 also stated the means which I recommended and employed for still further preventing the progress of cholera, I shall refrain from troubling you with any additional remarks; and remain,

Your obedient Servant, Lynn, Sept. 99th, 1832.

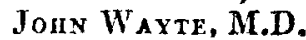
TRFATIENT OF THE

\section{MALIGNANT CHOLERA}

\section{AT}

\section{ST. THOMAS'S, EXETER.*}

\section{To the Secretary of the Cantrat Board of Healti.}

SIR,-In compliance with a request of the Central Board of Health, I have the lionour to communicate the following short outline of the treatment of cholera. The total number of cases occurring under my care, in the parish of St. Thomas, near Exeter, was $18^{2}$, of whom 21 died, and 161 recovered.

$A$ very large proportion of these (about 150) were seen previous to the stage of collapse, of whom all but 6 recovered. My usual plan of treatment in the commencement of the disease, was to bleed, from 6 to 12 ounces, and give a scruple of calomel, adding a grain and half of opium when purging was profuse; this plan in the very early stage is often found sufficient to arrest the disease, dark bilious evacuations being soon produced. The bleeding in general gives almost instant relief to the distressing symptoms of oppression about the precordia, and to the cramps.

When the vomiting continues urgent, I have given the saline draught in a state of effervescence with great advantage; if the disease does not yield, the calomel is repeated in doses proportioned to the urgency of the case, until salivation is produced, and

* Commnnicated by the Central Board of Health. 